\title{
Tale Of Two Mergers: A Case Study In Leading Change
}

\author{
Pamela Ann Gordon, Ph.D., University of Phoenix, USA
}

\begin{abstract}
The case study examines $P$ Pharmaceuticals' horizontal merger experiences; first with $S$ Pharmaceuticals, and later with U Pharmaceuticals. The case compares and contrasts each merger process from leading and communicating the change effort to the resultant transformations in corporate culture. As the case study unfolds, the aftermath of leading change and the resulting corporate merger outcomes are discussed.
\end{abstract}

Keywords: Leading Change; Communicating Change; Cultural Change; Sustaining Change

\section{INTRODUCTION}

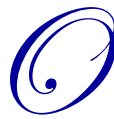

rganizational communication experts, Richmond and McCroskey (2009) suggested that there are five stages in the change adoption process: knowledge, persuasion, decision, implementation, and confirmation. In the first stage, knowledge, the idea for change comes to fruition. The second stage, persuasion, is when the idea is analyzed to see if making the change is a possibility and assess feelings toward the idea. The third stage, decision, is probably the most important because it determines whether or not to move forward with making the change, or abandoning the idea altogether. The fourth stage, implementation, is moving from the idea to action. The first three stages tend to focus heavily on individual thoughts and processes, while the implementation stage involves the entire organization. The final stage, confirmation, is the assessment of the change initiative outcome (Richmond \& McCoskey).

The change adoption process can be effectively utilized in various business strategies. Organizational business strategies are planned measures used to support an organization in meeting corporate objectives and to promote a competitive advantage versus rival firms (Muduli, 2012). One type of business strategy is the corporate merger. The three most common types of mergers are vertical, horizontal, and conglomerate. The vertical merger takes place between companies that are in different parts of a related business; for example, a merger between a manufacturer and supplier. A horizontal merger involves companies in the same industry. This type of merger results in the expansion or diversification of the product line, and promotes increased market power. When companies in unrelated industries merge and pool resources, the newly formed organization becomes a conglomerate (Nichols, McHugh, \& McHugh, 2012). According to Ozmel (2006), organizational entities merge "to strengthen their market position, to expand their businesses, to exploit other firms' complementary assets, or to realize efficiency gains by restructuring their businesses on a global basis" (p. 3).

This case study examines one company's experiences during two separate horizontal merger transactions. All three companies involved in the two mergers were large, multinational firms practicing decentralized management. In a constantly changing environment, forming a world-leading research -based pharmaceutical company was the ultimate goal for each merger. While in many cases, mergers have a primary initiating company, in the case study presented below, each merger was presented to employees as a mutual decision resulting from collaborative organizational meetings between senior level executives of each firm. Mergers, in general, can be very daunting because the entire fiber of the organization may change - polices, procedures, structures, and culture, have the potential to change (Morrissey, 2013). Throughout the case, we explore the processes that transpire in order to maintain the day-to-day operations while planning and implementing massive upcoming changes. As the case unfolds, readers are able to examine the procedures implemented throughout each merger and analyze which processes lead to positive outcomes. 


\section{THEORETICAL FRAMEWORK}

In reality, senior level management personnel and the Board of Directors influence the blueprint for organizational merger transactions, with most of the actual details orchestrated by the legal and regulatory teams of the merging companies. Very few employees have access to these processes. However, all employees are influential in helping to achieve the goals of any change initiative. The theoretical framework for this case study embraces the seminal work of Kotter's (1996) eight step process for leading change.

Kotter (1996) devised the following eight stages for successful transformations:

1. Create a sense of need regarding the initiative

2. $\quad$ Formulate teams to manage the process

3. Establish a clear picture of the intended outcome

4. Clearly convey the intended outcome

5. Encourage action and calculated risk-taking

6. Establish short-term milestones

7. Create momentum that leads to additional change

8. Embrace a new culture based upon the changes

Following this framework encourages employees to embrace the change process and become change agents to further ensure the initiative's ultimate success (Whelan-Berry \& Somerville, 2010).

\section{BACKGROUND}

P Pharmaceuticals and S Pharmaceuticals were multinational organizations with corporate headquarters for both companies located in England. Both companies maintained operational headquarters in countries throughout the world. Each operational headquarters practiced a decentralized management structure. P pharmaceuticals and $S$ pharmaceuticals presented with extensive pedigrees in healthcare and were pioneers in many areas of science and medicine, especially in the encouragement of human welfare. Prior to the merger, P Pharmaceuticals was the world's leading pharmaceutical company in sales dollars and market share of the international market.

According to The Association of the British Pharmaceutical Industry (2013), success in the United States is imperative to the international growth of any pharmaceutical company, as it represents approximately $35 \%$ of the global value of the market for medicines. Both P Pharmaceuticals and S Pharmaceuticals were major forces in the market with growth accelerated by products that rapidly became world leaders in their therapeutic classes. Prior to the merger, each company achieved annual sales in the United States equal to more than $40 \%$ of global turnover and provided the platforms for dynamic growth.

\section{INITIAL MERGER PLANS}

The actual word about a formal merger between P Pharmaceuticals and S Pharmaceuticals came in February. For the most part, employees at both companies were relieved when they heard the announcement of the actual companies involved in the merger. From a corporate merger standpoint, the combined current product portfolio, pipeline of future products, and geographic networks would position the new PS Pharmaceuticals at the forefront of the global healthcare industry. From a cultural and philosophical standpoint, it was a marriage made in heaven. Both companies traced their historical beginnings back to England. Both companies acquired a United States presence around the same time. In addition, corporate headquarters buildings for both companies were located in the same city, a few short miles from one another. From a competition standpoint, there was no overlap in product lines, so they were not direct competitors. From an organizational culture standpoint, the merger looked positive. The commonalities encouraged a positive perception of what the new company would look like once formed. 


\section{LAYING THE FOUNDATION}

After the merger agreement was formally announced, the real work began. Senior management from both companies sent announcements detailing what the standard operating procedures would be for the next several months (Lewis, Schmisseur, Stephens, \& Weir, 2006). The goal was to be fully integrated by August and a fabulous week-long new company launch celebration in a major city was promised for September. Consequently, employees had six months to implement the merger strategy and prepare to celebrate the birth of the new company. The hard work was about to begin. Looking forward to the celebration goal encouraged a team atmosphere and mindset.

The initial stages of the implementation followed a top-down strategy (Marks \& Mirvis, 2011). Outside consultants were hired to help with the development of size, strategy, and alignment of the business. In addition, a transition team was organized with members from both companies and representing all levels of the corporate workforce. The team was in charge of implementing an action plan blueprint so that all leaders in every department followed a unified plan in achieving the transitional steps. The first order of business was the announcement of the new upper management team. The team was a true blending of talents, with members of both companies being named to new positions. Those who were not offered positions were offered the golden parachute - lucrative severance packages or early retirement options.

Both companies historically had very strong and structured human resource practices in place regarding performance appraisals and annual reviews. Therefore, the selection process for employees being invited to move forward with the new company became a best of the best determination. All employees submitted their resumes and vied for positions within the new company. Newly named upper managers chose their next-level-down direct reports and the process continued in that manner until all positions were filled. Once again, current employees who were not invited to join the new company were offered substantial severance packages and additional outplacement services to assist with a smooth transition. Approximately $12 \%$ of employees worldwide did not move forward with the newly formed company.

\section{THE CHANGE EFFORT}

After all employees were identified, the real excitement began. Senior management (with recommendations from the consulting firm) rolled out the product divisional alignment. The new divisions were comprised of products from both former companies. This was great news. This meant that every single employee, regardless of company heritage, would learn and have responsibilities for selling new products. In essence, everyone was on equal footing - no one remained in his or her original comfort zone.

Part of any positive change entails calculated, prudent risk-taking (Whelan-Berry \& Somerville, 2010). PS Pharmaceuticals certainly embraced this concept. The training initiative for the sales team was massive. The company made a decision to pull the sales teams out of the field for three months and fully retrain everyone. This meant no sales representatives would be calling on doctors or healthcare professionals to promote products for three months. The very real risk was that sales would drop and the competition could capture the business. However, like any good change agents, PS Pharmaceuticals organizational leaders kept customers abreast of the merger plans and ensuing processes. Physicians and healthcare customers knew that the extensive retraining would ultimately translate into benefits for them because they would have the most knowledgeable and the best trained sales force as their medical resource. Before sales personnel left the field, their top targeted physician customers received three months of samples and the company implemented a massive customer response team to manage customers for the entire three months.

\section{SETTLING IN}

The overall climate during the six month integration period was one of hope, trust, and excitement. Throughout the entire period, the communication process kept everyone apprised of the situation. Throughout the United States, local and regional Town Hall meetings were held to provide updates, answer questions, and alleviate concerns. Voicemails, emails, letters and surprise gifts arrived to keep morale and anticipation at high levels. New friendships were formed and by the end of the integration period, the us and them philosophy was replaced by our philosophy (Vazirani \& Mohapatra, 2012). 
The PS Pharmaceuticals launch celebration was a party to remember! It was truly a united celebration for successfully achieving a common goal. Employees felt as though they cleared the first hurdle of the merger. In late September, employees reentered the business arena as PS Pharmaceuticals, with everyone committed and proud to be a member of the new organizational team.

\section{THE SECOND MERGER}

Five years after the initial merger, PS Pharmaceuticals entertained the possibility of another merger opportunity with U Pharmaceuticals. U Pharmaceuticals was also a multinational company with corporate headquarters in England and operational headquarters located in numerous countries. Similar to PS Pharmaceuticals, U Pharmaceuticals also followed a decentralized management structure. This time, initial negotiation information was carried out behind the scenes and employees were not as knowledgeable regarding what was happening. The first negotiation meetings did not lead to a successful outcome. During a National Sales Managers Meeting in January, the National Sales Manager told meeting attendees that the merger was not going to take place. He also mentioned that it was probably a blessing in disguise that the merger did not occur since the corporate cultures of the two companies were vastly different. News reports during that time period revealed that negotiations between the two companies failed in this first attempt to merge due to a clash of egos at the leadership level. However, the rationale for the merger was the same as the previous merger: combined product portfolio, pipeline of future products, and geographic networks would position the new company at the forefront of the global healthcare industry.

\section{HISTORICAL RELATIONSHIPS}

Unlike the first merger where the two companies never overlapped product lines, the second merger involved companies sharing a competitive history. U Pharmaceuticals originally launched a major product with no direct competition. For five years, the company cornered the market share and was the leader in this untapped market. Due to having no direct competition and the overall corporate-centric philosophy of the company, the new product was sold with very little emphasis placed on promotional efforts.

P Pharmaceuticals launched their product into this market which was a direct competitor, along with being a new and improved product. Since P Pharmaceuticals was new to the United States at that time, the number of employed sales representations could not adequately compete with the sales force size of U Pharmaceuticals. In order to level the playing field and ensure sales market penetration, P Pharmaceuticals contracted with a wellestablished pharmaceutical company that would help to co-promote the product. In addition, P Pharmaceuticals implemented unique marketing strategies that expanded disease awareness to physicians, healthcare workers, and patients. The product benefits coupled with this customer-centric philosophy ultimately led to the $\mathrm{P}$ Pharmaceuticals' product becoming the best-selling drug in history and overtaking the market share dominance from U Pharmaceuticals.

\section{THE SECOND CHANGE EFFORT}

Exactly one year after the initial failed merger attempt with U Pharmaceuticals, the second attempt succeeded and the merger occurred. Employees in both companies were not as knowledgeable of the behind-thescenes negotiations as they were with the PS Pharmaceutical merger. In this merger, two separate transition teams were created - one for each company and no plans for a unified culture were ever expressed Several key leaders from PS Pharmaceuticals chose not to move forward with the new company. Approximately $10 \%$ of employees worldwide lost their jobs in this merger, mostly from the sales and administration side of the business. An overall feeling of distrust and disappointment permeated throughout all levels of both companies due to past competitive interactions.

Another key decision was the name of the new company. The new company name eliminated the reference to S Pharmaceuticals; so, the new company became known as PU Pharmaceuticals. This action immediately alienated the S Pharmaceutical-heritage employees, as the perception evolved that they were not an integral part of the new organization. 
Town Hall meetings and communication occurred during the transition period; however, the emphasis was more related to how practices would remain the same, rather than promoting an integration process. While sharing a new name, both company headquarters remained separate - approximate 375 flight miles apart. One new sales team was formed that integrated both companies' product lines; however, employees selected for this team were told that the promotional emphasis would remain with their heritage products and very little cross-training occurred. To this day, the corporate culture remains disjointed since neither company willingly embraces a new, combined culture.

\section{COMPARING AND CONTRASTING MERGERS}

Both mergers achieved the goals of improving the company's presence in new therapeutic markets and implementing unique ways of promoting older, heritage products. At the time of each merger, initial cost savings produced increased financial revenue. In addition, stock value generated positive returns, at least in the short term. According to financial analysts, the PS merger generated 3.8 billion in net shareholder value. Alternately, two years after the PU merger, the stock share price was half of its previous value.

The actual change processes for each merger resulted in different cultural outcomes. The first merger produced a marriage made in heaven mindset, while the second merger was viewed more as a marriage of convenience. The PS merger closely followed Kotter's (1996) process for successfully leading change, while the PU merger appeared to be a rushed, dysfunctional process that overlooked many of the structural methods required to ensure a smooth employee transition to a new corporate culture (Marks \& Mirvis, 2011).

The outcome challenges faced in the second merger were not unusual. Bohlander and Snell (2007) posited that very few mergers (approximately 15 percent) actually achieve the planned objectives. Several reasons can be cited for merger failures. The new organization in the first merger discussed in this case study instituted key human resource management practices of staffing, training and development, and compensation "to ensure employees are in the proper jobs, have the appropriate skills, and are compensated and rewarded accordingly" (Buiter \& Harris, 2013, p. 20). The second merger did not follow these practices.

In addition to poor implementation of key HR practices, another main cause for disappointing merger results seems to be a lack of cultural collaboration within the newly formed company. Recklies (2001) stated that it is important in merger situations for the companies to decide well in advance whether they will adopt the existing culture of one of the former organizations or if they will create a new blended culture. A focus on building the postmerger corporate culture helps to ensure a smooth integration, the creation of new loyalties, and minimizes destructive conflict and tension (Harman, 2002). Identifying social networks of change agents within the newly formed company may be a practical solution in building a new corporate culture. Interestingly, Yamanoi and Sayama (2013) discovered that post-merger, the social networks of middle managers and frontline workers were more effective in promoting an integrated corporate culture, as opposed to the social networks between top executives, who had a lesser impact on influencing cultural integration. Finally, clear, open communication serves to reinforce the cultural foundation in a newly merged organization. The acculturation system must consist of how to develop regular dialogues, enhanced shared goals, shared knowledge about differences and similarities in norms, values, and expectations making agreements, monitoring conformity and agreements, proper handling of nonconformity and in advance, agreement on conflict resolution (Vazirani \& Mohapatra, 2012, p. 36).

The PS merger achieved cultural assimilation and integration. Blending work teams with representatives from each company paved the way for a new culture to evolve with each partner contributing toward a synergistic outcome. A strategic communication plan promoted a unified workforce throughout each phase of the merger. Alternately, the PU merger resulted in a cultural atmosphere of alienation and separation. Both companies attempted to retain their own cultures and no effort was made to create a new joint culture or fully accept one culture as the preferred new one. No attempts were made to blend workforces. While daily operational components were eventually aligned, the cultural transformation remained plural. Hammer and Falik (2004) emphasized that separate cultures can be maintained in merger situations; however, this should be clearly communicated to all employees during each phase of the integration process as the desired outcome. Unfortunately, this type of communication did not occur and the newly created workforce exhibited resistance to the overall change due to lack of understanding of the future plan. 


\section{CONCLUSION}

The dynamic business environment is one that requires inevitable and constant change. Organizational leaders need to effectively lead and sustain change initiatives within their organizations. Not all mergers are happy or successful, and certainly no organizational change is stress-free or problem-free. The two mergers discussed in this case present vastly different ways to plan, organize, and implement a merger change effort. The differences discussed in this case study led to two distinctly diverse cultural merger outcomes.

\section{DISCUSSION QUESTIONS}

The following questions serve as a springboard for more in-depth discussion in both face-to-face and online classes. The subject matter in this case study is relevant to undergraduate and graduate-level courses in Business Communications, General \& Strategic Management, Human Resource Management, Leadership, and Organizational Behavior.

1. Compare and contrast the implemented change processes between the two merger events.

2. Discuss what interpersonal communication skills are needed by organizational leaders, managers, and staff employees during times of change?

3. Discuss how to implement cultural change during mergers.

4. The second merger discussed in this case study did not result in a positive change experience. What could organizational leaders have done differently to ensure a more positive outcome?

5. What strategies can PU Pharmaceuticals implement now (long after the merger) to promote a more positive organizational climate?

\section{AUTHOR INFORMATION}

Dr. Pamela Ann Gordon (Ph.D., University of Phoenix) earned her doctorate in Business Administration with a specialization in Management from Northcentral University in 2008. Her three master's degrees are in Human Resource Management; Organization and Leadership; and an MBA with a specialization in Marketing. She has 22 years of experience in the pharmaceutical industry, with 17 of those years in corporate management/leadership positions. She has more than 10 years of post-secondary teaching experience and currently works for University of Phoenix fostering faculty development. Her research interests are in the areas of management/leadership, organizational behavior, marketing, and human resource management.

\section{REFERENCES}

Bohlander, G., \& Snell, S. (2007). Managing human resources (14th ed.). Mason, OH: Thomson South-Western. Buiter, J. E. M., \& Harris, C. M. (2013, Autumn). Post merger influences of human resource practices and organizational leadership on employee perceptions and extra-role behaviors. SAM Advanced Management Journal, 78(4), 14-22.

Hammer, B., \& Falik, S. (2004, June). Corporate mergers and acquisitions: A guide to leading to transition. Retrieved from http://www.hammerassociatesllc.com/articles/LeadingThruTransition.pdf.

Harman, K. (2002, July). Merging divergent campus cultures into coherent educational communities: Challenges for higher education leaders. Higher Education, 44(1), 91-114.

Kotter, J. P. (1996). Leading change. Boston, MA: Harvard Business School Press.

Lewis, L. K., Schmisseur, A, M., Stephens, K. K., \& Weir, K.E. (2006, April). Advice on communicating during organizational change. Journal of Business Communication, 43(2), 113-137.

Marks, M. L., \& Mirvis, P. H. (2011, November/December). A framework for the human resources role in managing culture in mergers and acquisitions. Human Resource Management, 50(6), 859-877.

Morrissey, B. (2013). Leading culture through times of organizational change. People \& Strategy, 36(4), 6-7.

Muduli, A. (2012, June). Business strategy, SHRM, HR outcome and organizational performance: Evidence from and Indian industry. Global Management Journal, 4(1/2), 111-125.

Nichols, W. G., McHugh, J. M., \& McHugh, S. M. (2012). Business: Connecting principles to practice. New York: McGraw Hill-Irwin. 
Ozmel, U. (2006). Effects of merger and antitrust laws on merger and acquisition activity: An international analysis. Paper presented at the American Sociological Association Annual Meeting, Montreal.

Recklies, O. (2001). Mergers and corporate culture. Retrieved from http://www.themanager.org/pdf/Merger_Culture.PDF

Richmond, V. P., \& McCroskey, J. C. (2009). Organizational Communication for survival: Making work, work $\left(4^{\text {th }}\right.$ ed.). New York: Pearson.

The Association of the British Pharmaceutical Industry. (2103). Global pharmaceutical industry and market. Retrieved from http://www.abpi.org.uk/industry-info/knowledge-hub/global-industry/Pages/industrymarket-.aspx

Vazirani, N. \& Mohapatra, S. (2012, March). Merging organizational culture through communication - Post mergers \& acquisitions. SIES Journal of Management, 8(1), 31-37.

Whelan-Berry, K. S., \& Somerville, K. A. (2010, June 1). Linking change drivers and the organizational change process: A review and synthesis. Journal of Change Management, 10(2), 175-193.

Yamanoi, J., \& Sayama, H. (2013, December). Post merger cultural integration from a social network perspective: A computational modeling approach. Computational \& Mathematical Organization Theory, 19(4), 516-537. 


\section{NOTES}

